\title{
Comparing two Power Supplies for Fast-Field Cycling Nuclear Magnetic Resonance Relaxometers
}

\author{
Power Losses and Performance
}

\author{
Marco Lima and Bruno Pereira \\ Department of Electrical and Computer Engineering \\ Instituto Superior Técnico \& INESC-ID - Universidade de \\ Lisboa \\ Lisboa, Portugal \\ marco.lima@tecnico.ulisboa.pt, \\ bruno.i.pereira@tecnico.ulisboa.pt \\ António Roque \\ Department of Electrical Engineering \\ ESTSetúbal - Instituto Politécnico de Setúbal \& INESC-ID \\ Setúbal, Portugal \\ antonio.roque@estsetubal.ips.pt
}

\begin{abstract}
The main power supply of a Fast Field-Cycling Nuclear Magnetic Resonance (FFC-NMR) is the key element comparing the performance of different solutions. The power supply is a current source that supplies a magnet being the current controlled in order to perform adjustable and repetitive current cycles. This power supply can be based on different topologies, operating principles and controlled using distinct techniques. If for the final users of this experimental technique the current cycles of the equipment is the core feature, for the developers also the power losses distribution needs to be analyzed in order to develop efficient solutions. In this paper, the power losses and the dynamic behavior of two solutions for the FFCNMR power supply are compared and discussed.
\end{abstract}

Keywords—power supply; power losses; fast field cycling NMR; DC/DC converter

\section{INTRODUCTION}

The Fast Field Cycling equipment (main blocks in Fig. 1) is used to determine the longitudinal relaxation time $\left(T_{1}\right)$ o different types of materials over a range of the magnetic flux density not covered by classical NMR techniques [1-4]. During a normalized FFC-NMR experiment, the magnet current cycles as represented in Fig. 2, being necessary, at least, define three current levels: the evolution level $I_{m E}$, the polarization level $I_{m P}$ and the detection level $I_{m D}$. Another core requirement of this technique are the switching times $t_{\text {on }}$ and $t_{\text {off }}$, which should be, typically, in the few milliseconds range. The polarization time $\Delta t_{P}$, the evolution time $\Delta t_{E}$ and the detection time $\Delta t_{D}$ are set according to the characteristics of the material under study. The overall cycle of current can last from few miliseconds to tens of seconds.

The power supplies of FFC-NMR apparatus have been evolved taking advantage of the evolution of power electronics devices and topologies [5-11].

\author{
Duarte M. Sousa \\ Department of Electrical and Computer Engineering \\ Instituto Superior Técnico \& INESC-ID - Universidade de \\ Lisboa \\ Lisboa, Portugal \\ duarte.sousa@tecnico.ulisboa.pt \\ Elmano Margato \\ Centro de Electrotecnia e Electrónica Industrial \\ ISEL \&INESC-ID \\ Lisboa, Portugal \\ efmargato@isel.ipl.pt
}

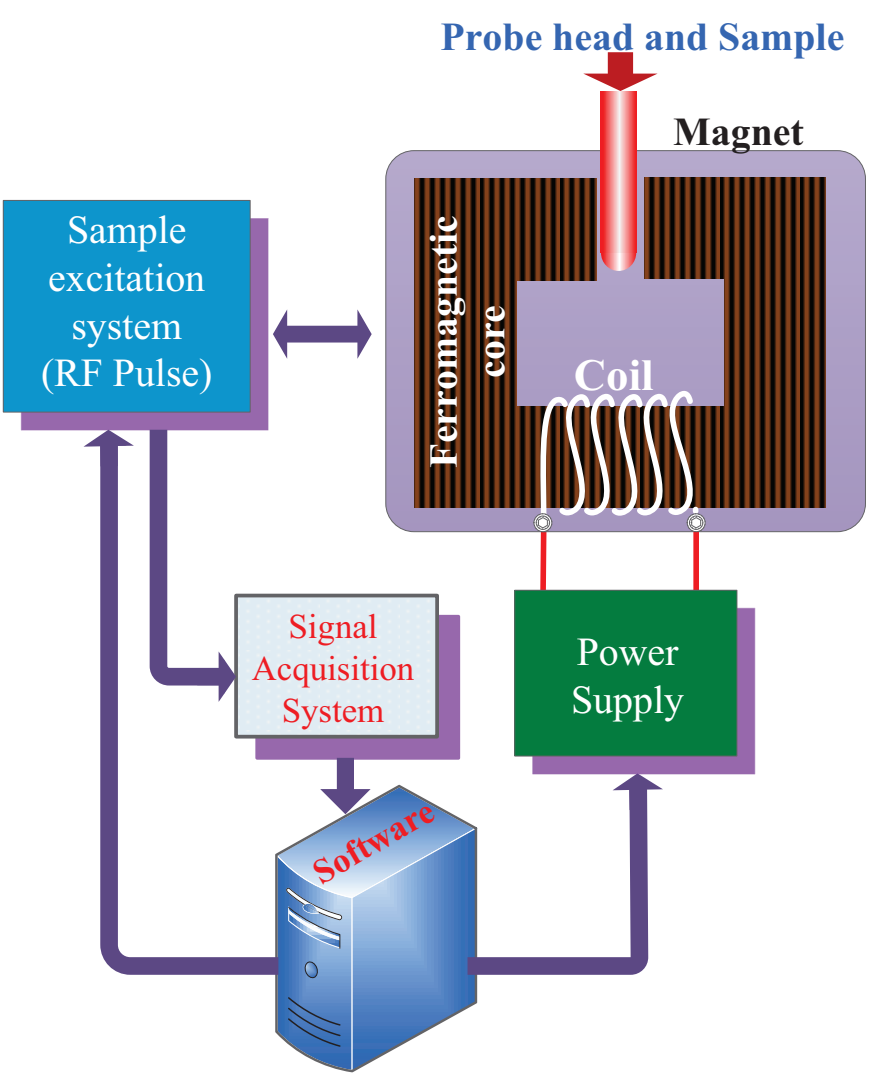

Fig. 1. Main blocks of a FFC NMR spectrometer

In this paper, two solutions for the power supply of the FFC-NMR spectrometer are described and compared based on their dynamic behavior and power losses. The proposed solutions for the power supply cover a flux density range corresponding to a magnet current range from 0 to $10 \mathrm{~A}$. 


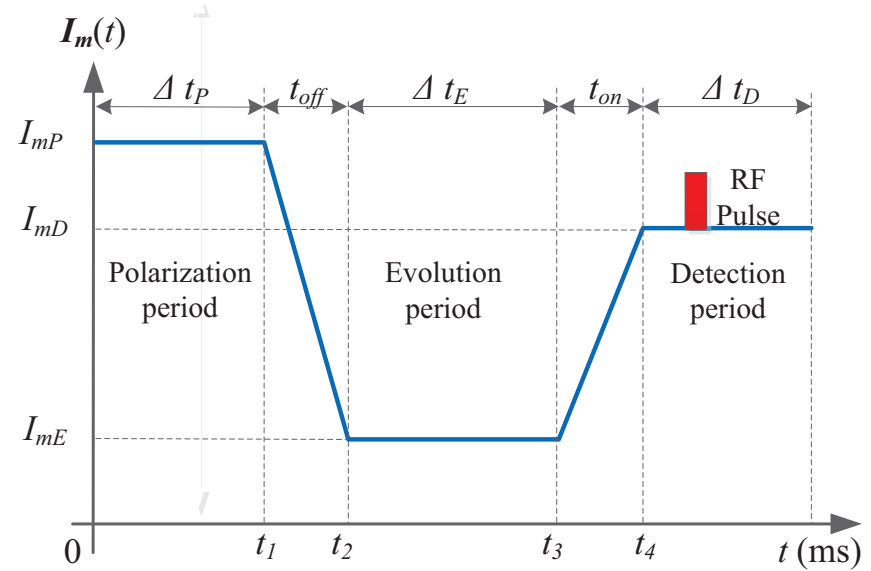

Fig. 2. Normalized current cycle

\section{ELECTRIC CIRCUITS}

The design of a power supply for FFC-NMR equipment can be done defining different targets, as for instance:

- $\quad$ the magnetic flux uniformity;

- $\quad$ the switching and settling times of the magnet current; or

- the minimization of the power losses.

These goals are framed by the main requirement of cycling the magnet current as represented in Fig. 2. Furthermore, the power supplies should allow fast current switching times and be controlled in order to get accurate and repetitive current levels [12-16].

Under this umbrella, the two solutions used as reference in this work should be able to control the magnet current from 0 to $10 \mathrm{~A}\left(\mathrm{I}_{\max }\right)$ and the settling times of the current should be within the range $3 \mathrm{~ms}$ to $6 \mathrm{~ms}$ [17-18].

\section{A. Solution with 2 voltage sources}

The circuit shown in Fig. 3 represents the "2 voltage sources" power supply. This circuit is constituted by two voltage sources ( $V$ and $\left.V_{a u x}\right)$, diodes $\left(D, D_{a u x}\right.$ and $\left.D_{R L}\right)$, switches (IGBTs $S$ and $S_{a u x}$ ) and a RC filter $\left(C\right.$ and $\left.R_{C}\right)$, being $R_{m}$ and $L_{m}$ the resistance and self-inductance of the magnet, respectively, and $I_{V}$ the current driven by the power source $V$ and $I_{\text {Vaux }}$ the current driven by the power source $V_{a u x}$.

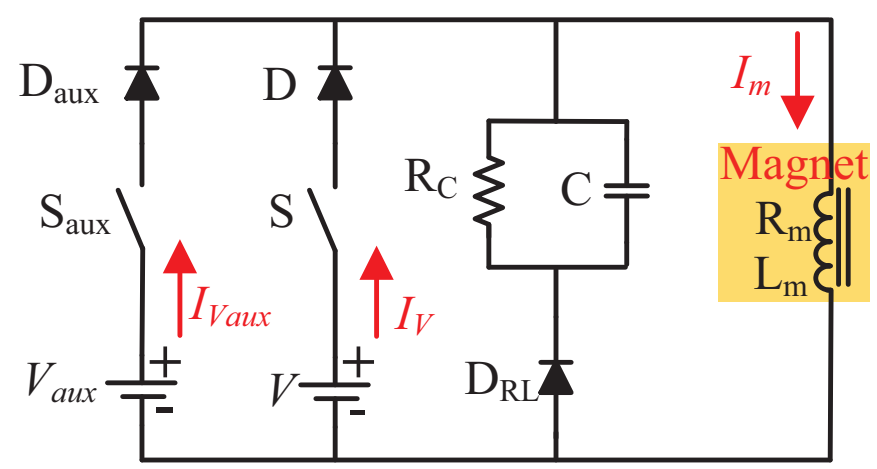

Fig. 3. Generic electric circuit of the 2 sources solution
The operation principle of this circuit depends on the switches $\left(S\right.$ and $\left.S_{\text {aux }}\right)$ states. The following three situations are considered (neglecting the diodes drop voltage):

- During $\Delta t_{P}, \Delta t_{E}$, and $\Delta t_{D}$ (steady-state): $S$ "under control ON/OFF" and $S_{a u x}$ "OFF", being the magnet current $\left(I_{m}\right)$ behavior represented by:

$V \cong R_{m} i_{m}+L_{m} \frac{d i_{m}}{d t}$

- During $t_{\text {on }}=t_{4}-t_{3}: S$ “OFF" and $S_{\text {aux }}$ "ON", being the magnet current $\left(I_{m}\right)$ behavior represented by:

$V_{\text {aux }} \cong R_{m} i_{m}+L_{m} \frac{d i_{m}}{d t}$

- During $t_{\text {off }}=t_{\underline{2}^{-}} t_{\underline{1}}: S$ "OFF" and $S_{a u x}$ "OFF", being the magnet current $\left(I_{m}\right)$ behavior represented by:

$\frac{1}{C} \int i_{m} d t \cong R_{m} i_{m}+L_{m} \frac{d i_{m}}{d t}$

To avoid short-circuits between the voltage source $V$ and the auxiliary voltage source $V_{a u x}$ a dead time is considered between the sequences "OFF-ON" of the switches.

The operating principle of this solution is in line with the requirements of the FFC-NMR technique.

B. Solution with 3 voltage sources

The circuit for the "3 voltage sources" solution is represented in Fig. 4.

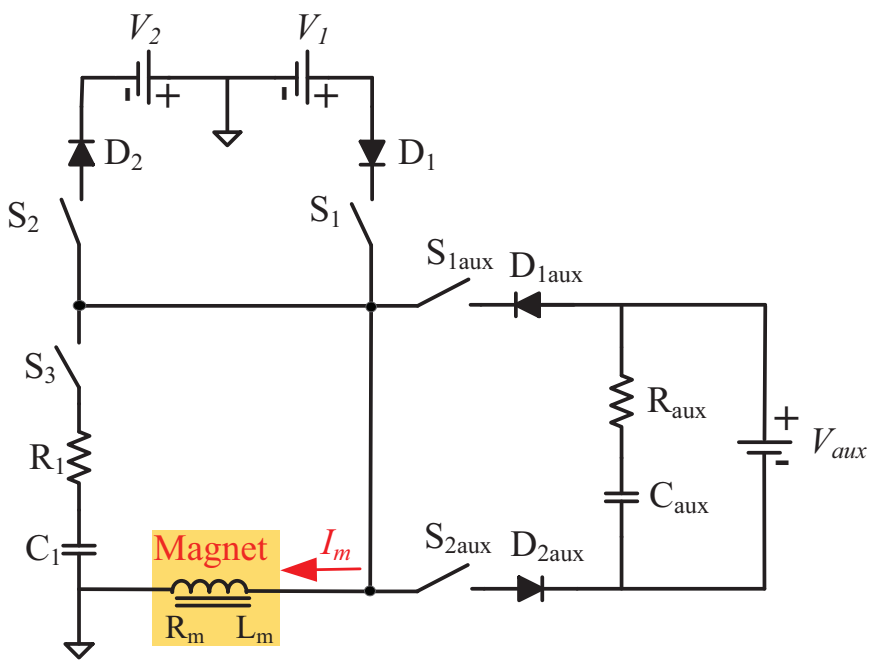

Fig. 4. Main circuit of the 3 sources solution

Owning this solution 5 switches, the "3 voltage sources" circuit is controlled in order to set the magnet current control for the following situations:

- Magnet current $\left(I_{m}\right)$ in steady-state within the range $\left[I_{\alpha}, I_{\max }\right]$, being the semiconductors: $S_{1}$ "under control ON/OFF"; $S_{3}$ "ON"; $S_{2}, S_{\text {laux }}$ and $S_{2 a u x}$ "OFF"). The equivalent circuit is represented in Fig. 5.

- Magnet current in steady-state within the range $\left[\begin{array}{ll}-I_{\alpha}, I_{\alpha}\end{array}\right]$ i.e., low current values, being the semiconductors: $S_{1}$ and $S_{2}$ "under control ON/OFF"; 
$S_{3}$ "ON"; $S_{\text {laux }}$ and $S_{2 a u x}$ "OFF". The equivalent circuit is represented in Fig. 6.

- Magnet current during $t_{\text {off }}$, being the semiconductors: $S_{3}$ and $S_{2 a u x}$ "ON"; $S_{1}, S_{2}$ and $S_{\text {laux }}$ "OFF". The equivalent circuit is represented in Fig. 7.

- Magnet current during $t_{o n}$, being the semiconductors: $S_{\text {laux }}$ "ON"; $S_{1}, S_{2}, S_{3}$ and $S_{2 \text { aux }}$ "OFF". The equivalent circuit is represented in Fig. 8.

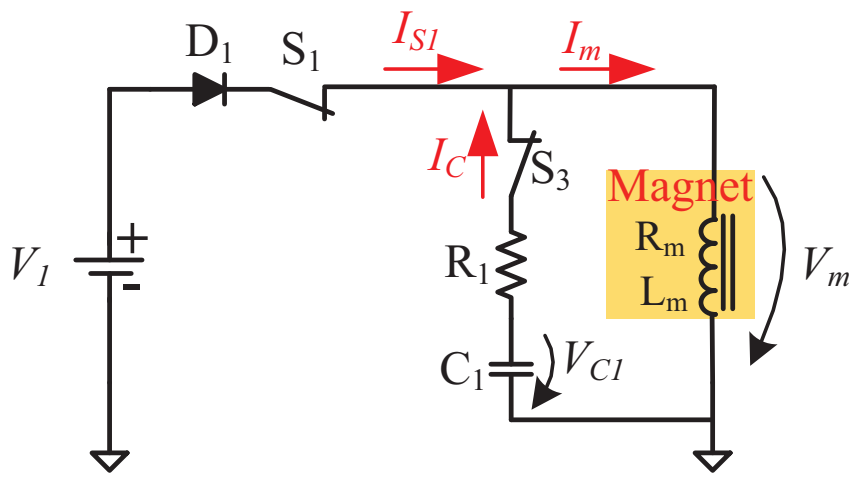

Fig. 5. Equivalent circuit for the current range $\left[\mathrm{I}_{\alpha}, \mathrm{I}_{\mathrm{max}}\right]$

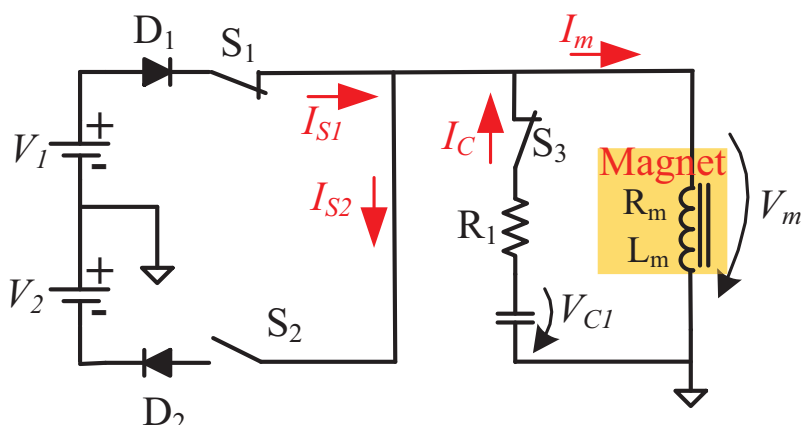

Fig. 6. Equivalent circuit for the current range $\left[-\mathrm{I}_{\alpha}, \mathrm{I}_{\alpha}\right]$

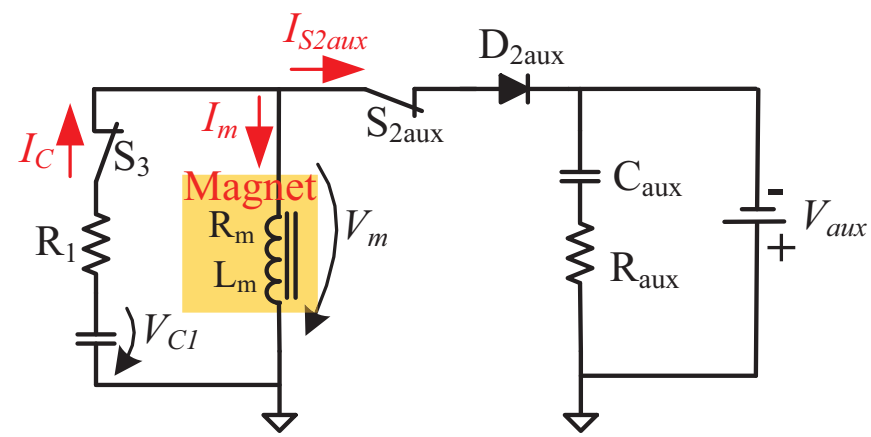

Fig. 7. Equivalent circuit for the current during $t_{\text {off }}$

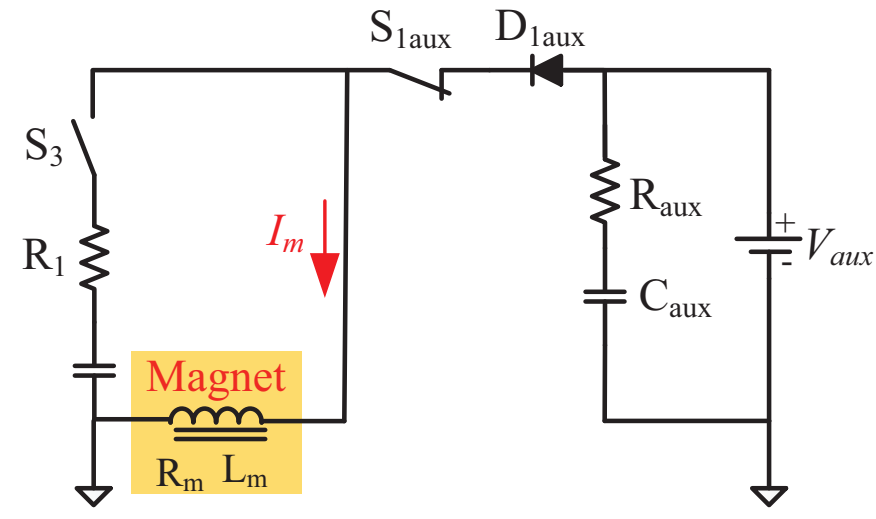

Fig. 8. Equivalent circuit for the current during $t_{\text {on }}$

\section{Power Losses}

Based on the operating modes of each solution, the power losses for these two power supplies during a normalized current cycle can be analyzed and compared considering the [19-20]:

- Power losses of the switches: switching losses and conduction losses;

- Joule losses of the magnet.

The approaches used to calculate the power losses for both solutions are described below, considering a normalized current cycle, with the following characteristics:

$$
\begin{aligned}
& I_{m l}=I_{m E}=2 \mathrm{~A} \\
& I_{m 2}=I_{m P}=I_{m D}=10 \mathrm{~A} ; \\
& \Delta t_{E}=t_{3}-t_{2}=100 \mathrm{~ms} ; \\
& \Delta t_{P} \approx \Delta t_{D}=500 \mathrm{~ms} ; \\
& t_{o n}=t_{4}-t_{3}=3.2 \mathrm{~ms} ; \\
& t_{o f f}=t_{2}-t_{1}=3.5 \mathrm{~ms} \\
& T=667 \mathrm{~ms} ; \\
& R_{m}=3 \Omega ; \\
& V_{O N_{-} \text {diodes }}=1.5 \mathrm{~V} ; \\
& V_{O N_{\text {_switches }}}=2.7 \mathrm{~V} ; \\
& V_{-}=50 \mathrm{~V} ; \\
& V_{l}=V_{2}=32 \mathrm{~V} \\
& V_{\text {aux }}=400 \mathrm{~V}
\end{aligned}
$$

\section{A. Solution with 2 voltage sources}

For the estimation of the Joule losses in the magnet are considered the power delivered by the voltage sources ( $V$ and $V_{\text {aux }}$ ) (Fig. 9) and the power losses in the magnet, $P_{R}=R_{m} I_{m}^{2}$ (Fig. 10).

For the current cycle used as reference, the average power delivered by the voltage sources are:

- Source $V: P_{V}=\frac{1}{T}\left[\left(\Delta t_{E}\right) I_{m 1} V+\left(\Delta t_{D}\right) I_{m 2} V\right]=445 \mathrm{~W}$;

- Source $V_{a u x}: P_{V_{a u x}}=\frac{1}{T}\left[\left(t_{o n}\right) \frac{I_{m 1} V_{a u x}+I_{m 2} V_{a u x}}{2}\right]=7.67 \mathrm{~W}$.

The power losses are:

- Diodes and switches: $P_{O N} \approx V_{O N} I_{S i_{a v}}=38.6 \mathrm{~W}$;

- $\quad$ Magnet: $P_{R}=R_{m} I_{m}^{2}=256.8 \mathrm{~W}$. 
Being $V_{O N}$ the drop voltage of diodes/switches when "ON" and $I_{S i_{a v}}$ the average current.

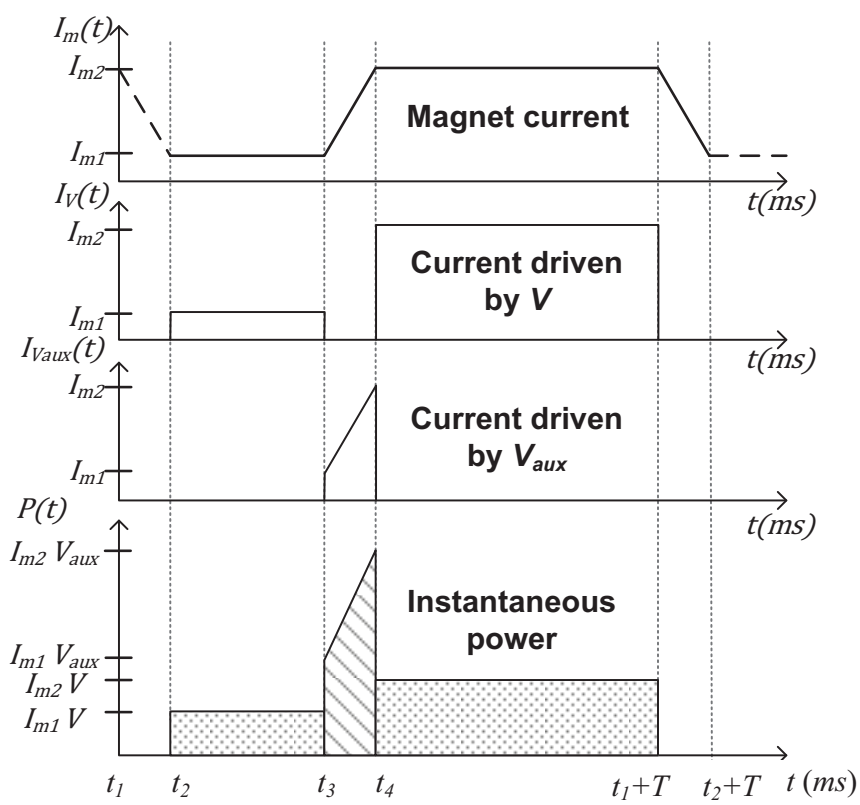

Fig. 9. Power delivered by the voltage sources during a current cycle

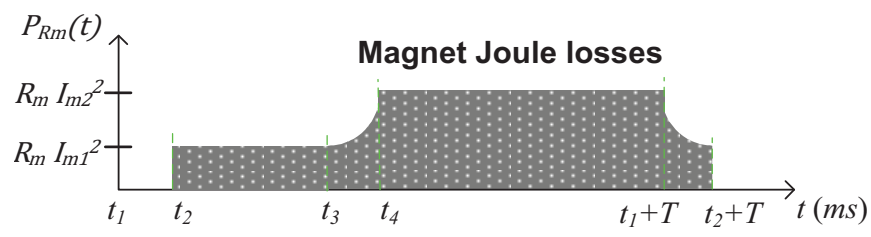

Fig. 10. Magnet power losses during a current cycle

\section{B. Solution with 3 voltage sources}

For similar conditions than the solution with 2 power sources, i.e., same procedure to estimate the power losses, in this case, the power losses distribution is summarized in Fig. 11 .

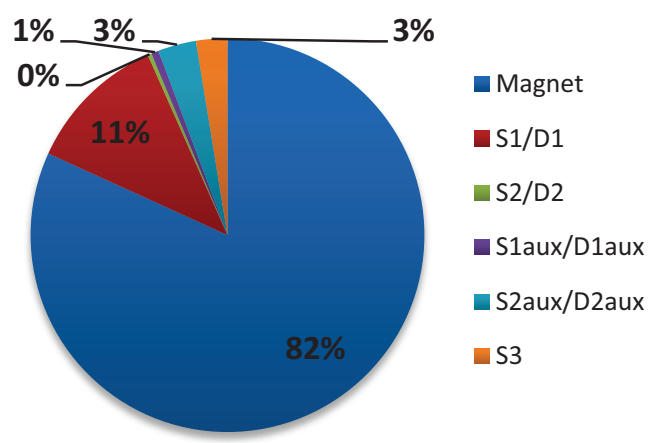

Fig. 11. Power losses distribution during a current cycle

The results shown in Fig. 11 are obtained considering that:

- Switching losses of the semiconductors:

$$
P_{S i}=V_{S_{i}} I_{S_{i}}\left(\frac{t_{o n}+t_{o f f}}{2 T}\right)
$$

- Conduction losses of the semiconductors:

$P c_{i}=V_{S i_{a v}} I_{S i_{a v}}$

Being $V_{S_{i}}$ and $V_{S i_{a v}}$ average voltage values, $I_{S_{i}}$ and $I_{S i_{a v}}$ average current values, and $T$ the reference period of a magnet current cycle.

\section{DYNAMIC BEHAVIOUR}

To analyze the dynamic behavior of these circuits, the magnet current is the most important variable, in particular the dynamic behavior of the magnet current during $t_{\text {on }}$ and $t_{\text {off }}[21]$.
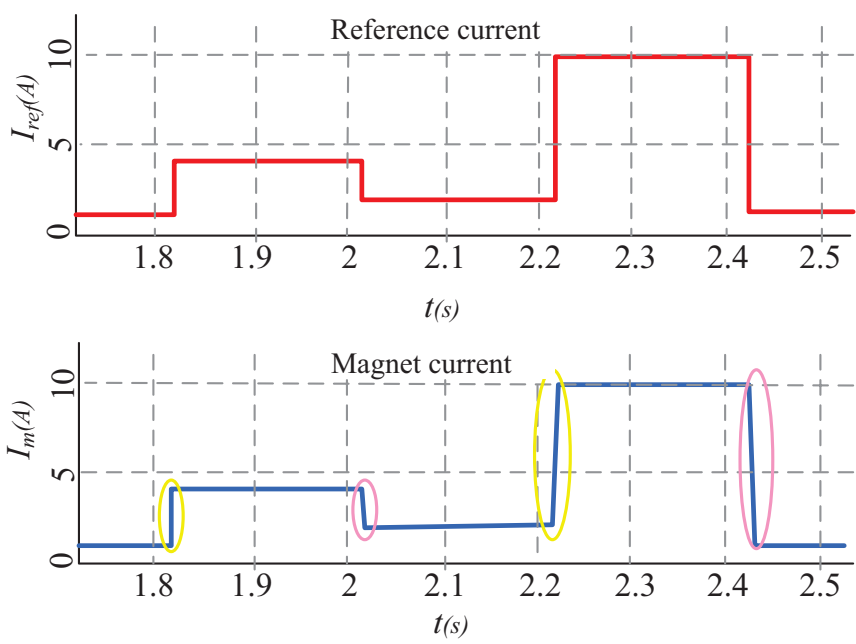

Fig. 12. Example of a global current cycle for the " 2 voltage sources" solution
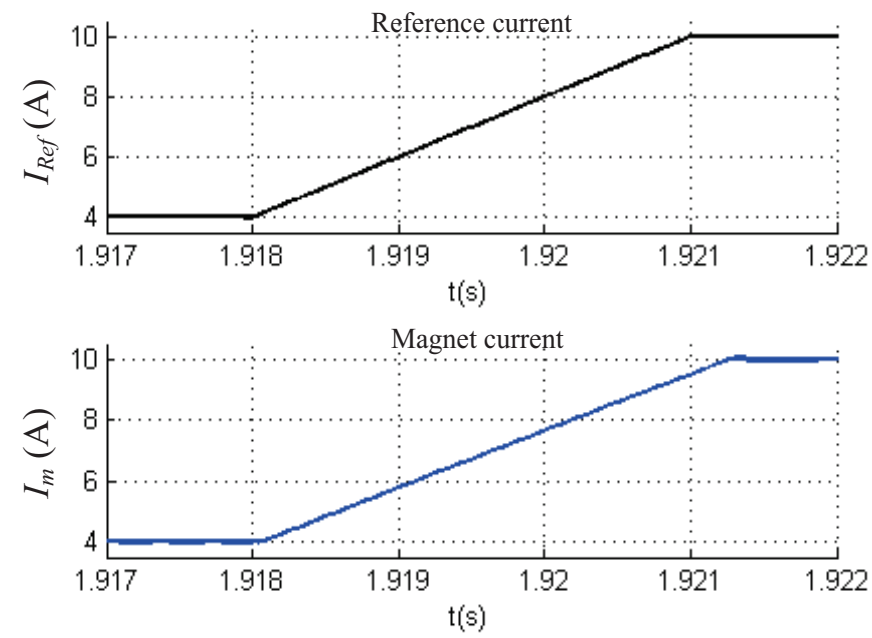

Fig. 13. Dynamic behavior of the magnet current during $t_{\text {on }}$ for the " 2 voltage sources" solution

For the "2 voltage sources", in Fig. 12 is shown an example of a magnet current cycle. In Fig. 13 and Fig. 14 are illustrated the dynamic behavior of the current during $t_{\text {on }}$ and $t_{\text {off }}$, respectively. To compare the dynamic performance of the 
two solutions, for the "3 voltage sources", in Fig. 15 is shown another example of a magnet current cycle. In Fig. 16 and Fig. 17 are illustrated the dynamic behavior of the current during $t_{\text {on }}$ and $t_{\text {off, }}$, respectively.
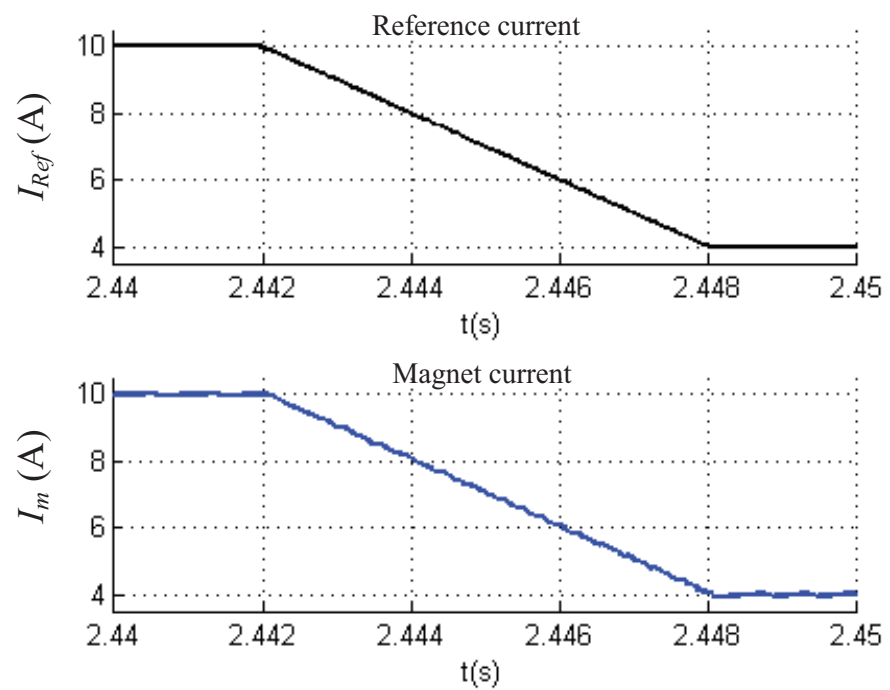

Fig. 14. Dynamic behavior of the magnet current during $t_{\text {off }}$ for the " 2 voltage sources" solution

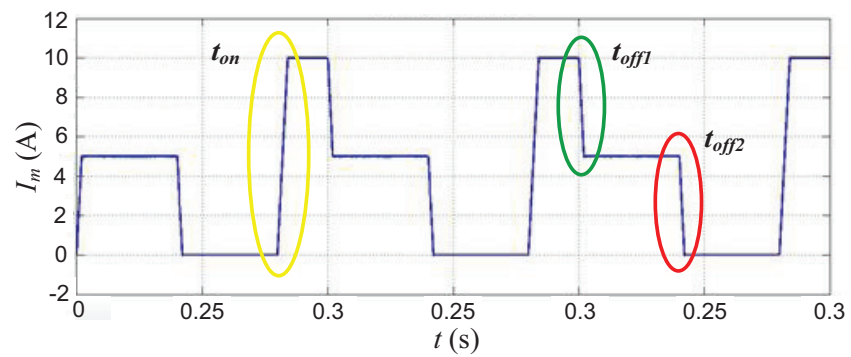

Fig. 15. Example of a current cycle for the "3 voltage sources" solution

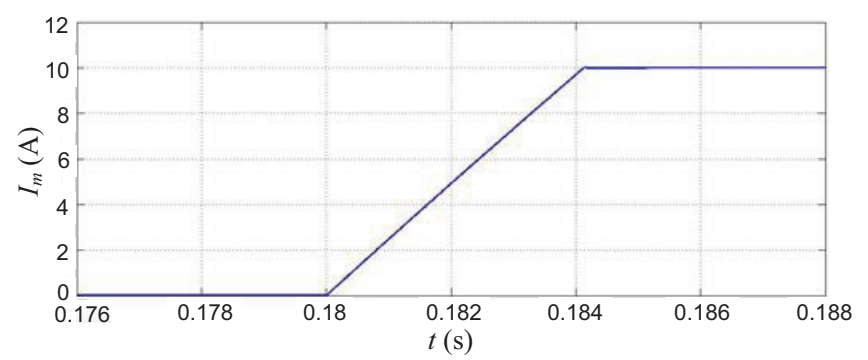

Fig. 16. Dynamic behavior of the magnet current during $t_{\text {on }}$ for the " 3 voltage sources" solution

\section{CONCLUSION}

The electric circuits presented in this paper allow obtaining results that are under the specifications of the FFC-NMR technique. For a magnet current up to $10 \mathrm{~A}$ and equivalent current cycles, the power consumption and the power losses are similar for both solutions.

The major challenge behind these systems is the cooling system due to its Joule losses. The " 2 voltage sources" owns fewer semiconductors and requires a less complex control system. For other hand, the " 3 voltage sources" solution is able to overcome technical issues related with parasitic magnetic fields and non-linearities of the magnetic load. Balancing "power losses + complexity of the solution" vs. "technical requirements of the FFC NMR technique", the "3 voltages sources" is a more versatile solution for this application.

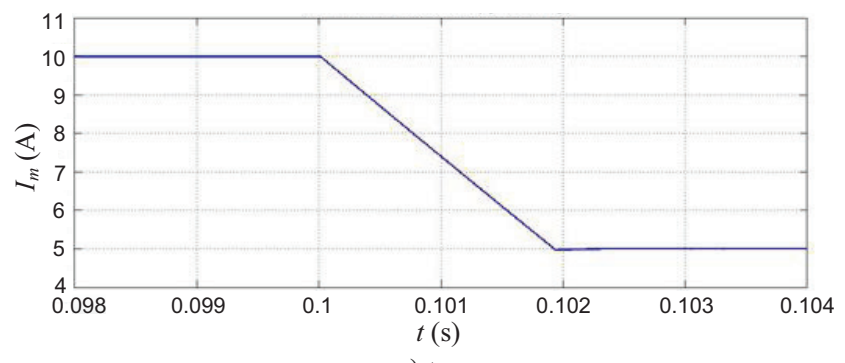

a) $t_{\text {off } 1}$

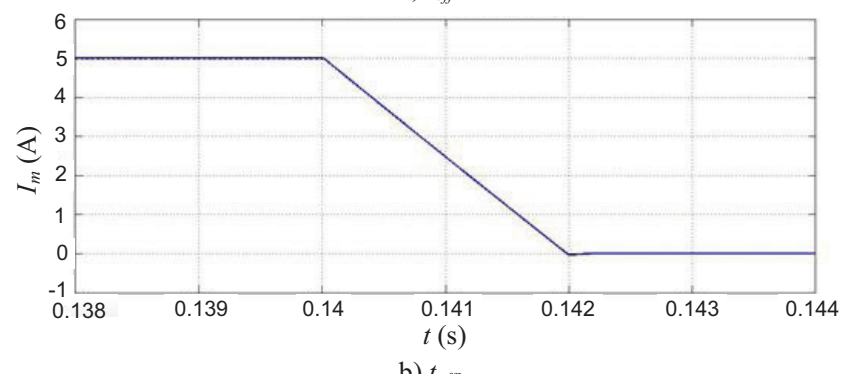

Fig. 17. Dynamic behavior of the magnet current during $t_{\text {off }}$ for the " 3 voltage sources" solution

\section{ACKNOWLEDGMENT}

FCT - Fundação para a Ciência e a Tecnologia, under project UID/CEC/50021/2013.

\section{REFERENCES}

[1] F. Noack, "NMR Field-Cycling Spectroscopy: Principles and Applications," Prog. NMR Spectrosc., vol. 18, pp. 171-276, 1986.

[2] R. Seitter, R. O. Kimmich, "Magnetic Resonance: Relaxometers," Encyclopedia of Spectroscopy and Spectrometry, Academic Press, London, pp. 2000-2008, 1999.

[3] E. Anoardo, G. Galli, G. Ferrante, "Fast-Field-Cycling NMR: Applications and Instrumentation," Applied Magnetic Resonance, vol. 20, pp. 365-404, 2001.

[4] R. Kimmich and E. Anoardo, "Field-Cycling NMR relaxometry," Progress in NMR Spectroscopy, 44, pp. 257-320, 2004.

[5] J. Constantin, J. Zajicek, F. Brown, "Fast Field-Cycling Nuclear Magnetic Resonance Spectrometer," Rev. Sci. Instrum., vol. 67, pp. 2113-2122, 1996.

[6] D. M. Sousa, E. Rommel, J. Santana, J. Fernando Silva, P. J. Sebastião, A. C. Ribeiro, "Power Supply for a Fast Field Cycling NMR Spectrometer Using IGBTs Operating in the Active Zone," 7th European Conference on Power Electronics and Applications (EPE1997), Trondheim, Norway, pp. 2.285-2.290, 1997.

[7] D. M. Sousa, P. A. L. Fernandes, G. D. Marques, A. C. Ribeiro, P. J. Sebastião: Novel Pulsed Switched Power Supply for a Fast Field Cycling NMR Spectrometer, Solid State Nuclear Magnetic Resonance, vol. 25, 2004, pp. 160-166

[8] D. M. Sousa, G. D. Marques, J. M. Cascais, P. J. Sebastião: Desktop Fast-Field Cycling Nuclear Magnetic Resonance Relaxometer, Solid State Nuclear Magnetic Resonance, vol. 38, 2010, pp. 36-43

[9] A. Roque, S. F. Pinto, J. Santana, Duarte M. Sousa, E. Margato, J. Maia, "Dynamic Behavior of Two Power Supplies for FFC NMR Relaxometers," IEEE International Conference on Industrial Technology - ICIT 2012, Athens - Greece, 2012. 
[10] D. M. Sousa, G. Marques and P. J. Sebastião, "Reducing the size of Fast Field Cycling NMR Spectrometers based on the use of IGBTs,," "IEEE ICIT 2009 - International Conference on Industrial Technology", Churchill - Australia, February 2009.

[11] M. Lima, D. M. Sousa, A. Roque, "Reversible Current Power Supply for Fast-Field Cycling Nuclear Magnetic Resonance Equipment," "EPE'15 - 17th European Conference on Power Electronics and Applications", Geneve, Switzerland, 8-10 September 2015.

[12] A. G. Redfield, W. Fite, H. E. Bleich, "Precision High Speed Current Regulators for Occasionally Switched Inductive Loads," Review of Scientific Instruments, vol. 39, pp. 710-715, 1968.

[13] A.Roque, D. M. Sousa E. Margato, J. Maia, "Current source of a FFC NMR relaxometer linearly controlled," EPE'13 - 15th European Conference on Power Electronics and Applications, Lille, France, 2013.

[14] Rong-Jong Wai, Yuan Ze, Bo-Han Chen, "High-Efficiency Dual-Input Interleaved DC-DC Converter for Reversible Power Sources", IEEE Transactions on Power Electronics, pp. 2903 - 2921, 2014.

[15] P. Scortaru, D.V. Nicolae, M. Cernat, Z. Puklus, "Reversible DC-to-DC converter for a dual voltage automotive system using zero voltage switching technique," 11 th International Conference on Optimization of
Electrical and Electronic Equipment (OPTIM 2008), pp. 251 - 258, 2008.

[16] Yue Wen, L. Shao, R. Fernandes, O. Trescases, "Current-mode bidirectional single-inductor three-port DC-DC converter for portable systems with PV power harvesting," 15th European Conference on Power Electronics and Applications (EPE), 2013.

[17] J. J. D'Azzo and C. H. Houpis, Linear Control System Analysis and Design: Conventional and Modern, 4th Edition, McGraw-Hill, 1995.

[18] K. Ogata, Modern Control Engineering, 5th Edition, Prentice-Hall, 2010

[19] Xuan-Dien Do, Seok-Kyun Han, Sang-Gug Lee, "Low power consumption for detecting current zero of synchronous DC-DC buck converter," SoC Design Conference (ISOCC), pp. 487 - 490, 2012.

[20] J. F. Silva, S. F. Pinto, Advanced Control of Switching Power Converters, Power Electronics Handbook, Elsevier, 3rd Edition, 2011.

[21] A. Roque, S. F. Pinto, J. Santana, Duarte M. Sousa, E. Margato, J. Maia, "Design of Current Power Sources for a FFC NMR Apparatus: A Comparison," Technological Innovation for Value Creation - DoCEIS 2012, Springer, pp. 299-308, 2012. 